\title{
Initial experience of G-POEM in Greece performed with a scissor-type knife and monitored by endoluminal functional imaging
}

\author{
Georgios Mavrogenis ${ }^{a}$, Anna Spanomanoli ${ }^{b}$, Fateh Bazerbachic \\ Mediterraneo Hospital, Athens, Greece; CentraCare, St Cloud Hospital, St Cloud, MN, USA
}

A 20-year-old male with a history of autism was referred for refractory postprandial vomiting and weight loss over the past 2 years. His nutrition was maintained through parenteral access and via percutaneous gastrostomy tube. Endoscopy showed esophagitis, a tight pylorus, and barium studies demonstrated delayed gastric transit. Botox injection at the distal antrum resulted in transient clinical improvement. Therefore, we proceeded with gastricperoral endoscopic myotomy (G-POEM) (Fig. 1) [1]. After tunneling, an endoscopic functional lumen imaging probe (EndoFLIP, Medtronic, Dublin, Ireland) was inserted across the pylorus. The distensibility index was measured at 5.2 $\mathrm{mm}^{2} / \mathrm{mm} \mathrm{Hg}$ (Fig. 2). Next, myotomy was performed with a scissor-type knife with insulated extremities to protect the duodenal mucosa (SB Knife, Sumitomo Bakelite Co. Ltd., Tokyo, Japan). The muscular fibers were grasped with the knife, the knife was slightly retracted away from the duodenal mucosa and the fibers were dissected (DryCut 3, VIO 3, ERBE, Tubingen, Germany). The distensibility index was then re-measured and improved to $18.8 \mathrm{~mm}^{2} / \mathrm{mm} \mathrm{Hg}$. The mucosotomy site was closed with an endoloop and clips. At 4 months of follow up, the patient had resumed oral alimentation, showed significant clinical improvement and had regained weight. To the best of our knowledge, this is the first reported case of G-POEM in Greece. We also demonstrate the efficacy of a scissor-type knife in achieving adequate myotomy, and illustrate the role of real-

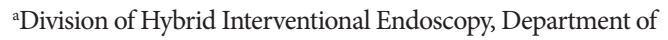
Gastroenterology, Mediterraneo Hospital, Athens, Greece (Georgios

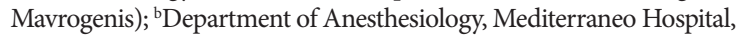
Athens, Greece (Anna Spanomanoli); 'CentraCare, St Cloud Hospital, Interventional Endoscopy Program, St Cloud, MN, USA (Fateh Bazerbachi)

Conflict of Interest: None

Correspondence to: Georgios Mavrogenis, Director of Hybrid Interventional Endoscopy, Department of Gastroenterology, Mediterraneo Hospital, Ilias 12, 16675 Athens, Greece, e-mail: mavrogenis@gmail.com

Received 14 July 2021; accepted 26 August 2021

published online 10 November 2021

DOI: https://doi.org/10.20524/aog.2021.0673

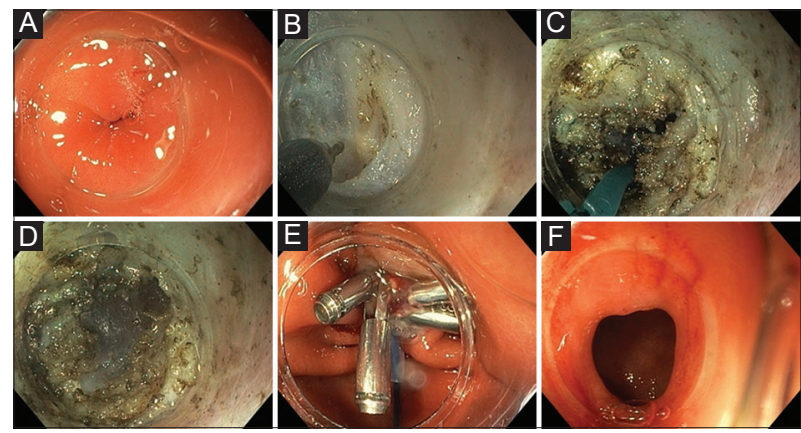

Figure 1 Endoscopic steps of G-POEM. (A) Spastic pylorus. (B) Tunneling. (C) Myotomy at 6 o'clock with a scissor-type knife. (D) Completion of myotomy. (E) Closure of the mucosotomy with a loop and clips. (F) Pyloric opening after the myotomy

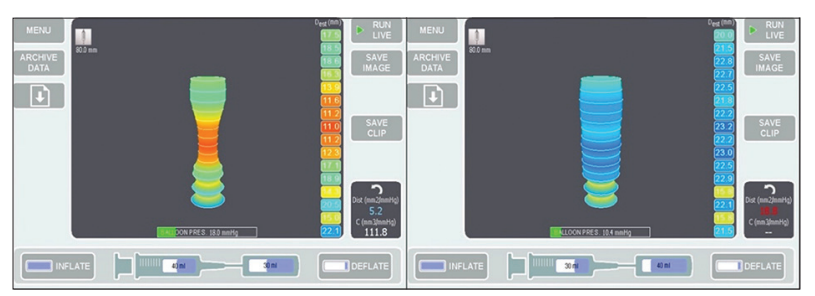

Figure 2 Endoluminal functional lumen imaging before (left) and after (right) myotomy, showing an increase of the distensibility index from 5.2 to $18.8 \mathrm{~mm}^{2} / \mathrm{mm} \mathrm{Hg}$. In addition, regression of the central highpressure area is noted after myotomy

time intraprocedural EndoFLIP to determine the adequacy of myotomy. However, given the lack of validated evidence examining the role of this method in G-POEM, it should be confirmed by prospective studies.

\section{Reference}

1. Aghaie Meybodi M, Qumseya BJ, Shakoor D, et al. Efficacy and feasibility of G-POEM in management of patients with refractory gastroparesis: a systematic review and meta-analysis. Endosc Int Open 2019;7:E322-E329. 